\title{
$\mathrm{PH} 101$
}

\section{Cultura y Ciudadanía cumple seis años en 2020 con un nuevo Encuentro que profundiza en su vocación transdisciplinar}

\begin{abstract}
En 2020 el programa Cultura y Ciudadanía, del Ministerio de Cultura y Deporte, y su Encuentro homónimo -como actividad seminal y principal-cumplirán seis años, tiempo y perspectiva suficientes para establecer valoraciones y articular algunas conclusiones significativas, aunque estas corresponde seguramente a otros realizarlas. Aquí trataremos de explicar los porqués y los cómos de este proyecto, que nació con el objetivo de abrir un espacio de reflexión e intercambio, investigación y diálogo, debate y colaboración, en torno a las políticas, procesos y prácticas culturales que han ido germinando y estableciéndose en los últimos tiempos.
\end{abstract}

Benito Burgos Barrantes, Rafael Sanz, Gonzalo Fernández Naves | Ministerio de Cultura y Deporte, Gobierno de España

URL de la contribución <www.iaph.es/revistaph/index.php/revistaph/article/view/4704>

Cultura y Ciudadanía surge en 2015 -dentro de la Subdirección General de Cooperación Cultural con las Comunidades Autónomas de la Dirección General de Industrias Culturales, Propiedad Intelectual y Cooperación del Ministerio de Cultura y Deporte- para compartir, vislumbrar y proponer formas de estar, pensar y hacer diferentes, en la constatación de cambios profundos en las formas de entender y abordar el pensamiento y la praxis cultural, reorganizadas cada vez más alrededor no tanto de objetos -materiales o inmateria-

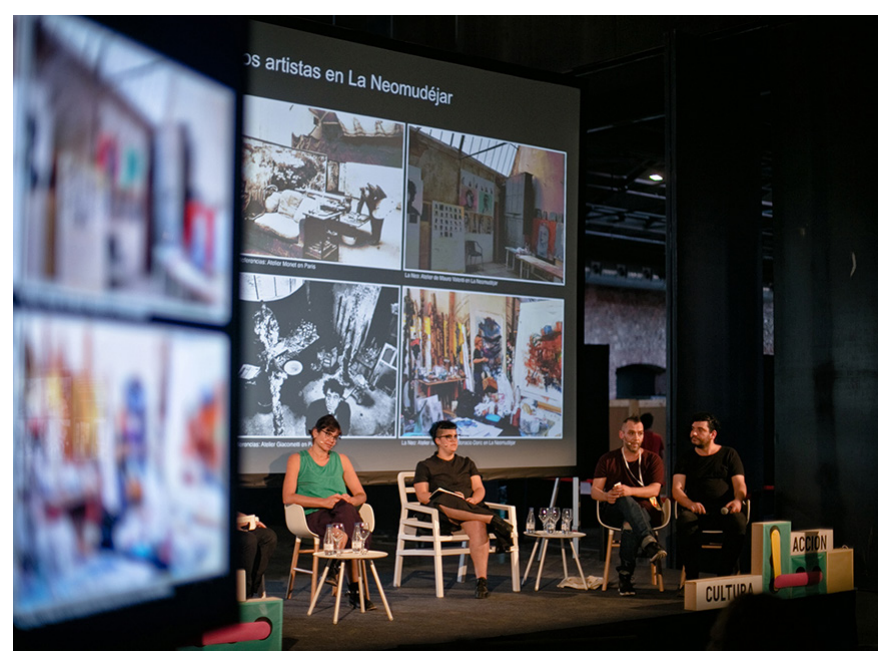

III Encuentro Cultura y Ciudadanía. Acceso, acción. Matadero Madrid, 2017 | foto Cultura y Ciudadanía, fuente de todas las imágenes que ilustran esta contribución les- como de sujetos -que devienen en agentes activos, no receptores pasivos, portadores de derechos de participación cultural-, basadas menos en la lógica mercantil y efímera del evento o el producto consumible y más en cambio en los procesos de intervención a medio y largo plazo.

El escenario de precariedad y crisis institucional y económica que se presenta tras el seísmo económico de 2008, unido al surgimiento de nuevas formas de entender el papel político y social de la ciudadanía bajo cláusulas más participativas, abre espacio en el contexto de las prácticas culturales a una amalgama de iniciativas diversas impulsadas desde distintos lugares, colectivos y agentes -por lo general al margen de lo institucionalcon una vocación eminentemente participativa, colaborativa y ciudadana. Que entienden la cultura como un espacio relacional de convivencia y negociación -bien común y derecho fundamental- donde, acogiéndose a una noción amplia del término, caben las prácticas artísticas, pero también esa deriva o vertiente antropológica donde la cultura funciona como exploración y ensamblaje del universo de lo social.

De alguna manera, Cultura y Ciudadanía responde y atiende a ese momento "histórico" de cambio de paradigma, de cierta emergencia por otorgar visibilidad, compartir o formalizar -legitimar, en suma- un pensamiento y unas prácticas que venían cristalizando en la última 
década en su propósito de generar una plataforma para el intercambio de conocimiento y experiencias, y para la creación de redes entre diversos agentes culturales que se mueven en lógicas comunes.

"Todo comienzo es inesperado", expresa Fernando Pessoa, y al menos en parte tal afirmación resulta cierta en nuestro caso ya que algunas de las narraciones y sendas que transitaría posteriormente el programa no estaban aún trazadas. Lo que es innegable es que el programa se ubica en ese contexto de cambio de sensibilidad, de "giro" hacia otras o nuevas prácticas y políticas culturales que, más allá de la dinámica tradicional de programación-consumo cultural, buscan activar procesos que redunden en una concepción de la cultura como bien común, como lugar de todos, a partir de dinámicas de participación, de mediación, de agenciamiento, de innovación social, de experimentación, de crítica... Su propio encaje a nivel ministerial, en una unidad de enfoque transversal y un campo de actuación basado en la colaboración entre Administraciones territoriales, permite adicionalmente incorporar y naturalizar dos ideas que son centrales dentro del programa: una visión de la cultura como un espacio de relaciones complejo, que desborda los límites disciplinares, sectoriales e institucionales -donde el patrimonio cultural ha de estar también necesariamente presente-; y una preocupación por visibilizar, legitimar y conectar experiencias de todo el territorio, con especial atención a la dimensión "micro", periférica y excéntrica, potencialmente innovadora, como lugar para la diversidad, la experimentación y la singularidad cultural. Cultura y Ciudadanía intenta abrir, dentro de la propia institución, un espacio de trabajo alter-institucional en el que ensayar, tensar sus límites y explorar sus problemáticas y contradicciones.

En noviembre de 2015 tuvo lugar el primer encuentro, Cultura Local y Construcción de Ciudadanía, modelado en su programa sobre la cultura local y de proximidad como vector de transformación, que sirvió para presentar las primeras líneas de trabajo, explorar otras y empezar a articular un espacio de debate, diálogo y colaboración con y entre múltiples y diversos agentes de todo el Estado, públicos y privados. A partir de entonces el programa se irá ensanchando y ramificando. La

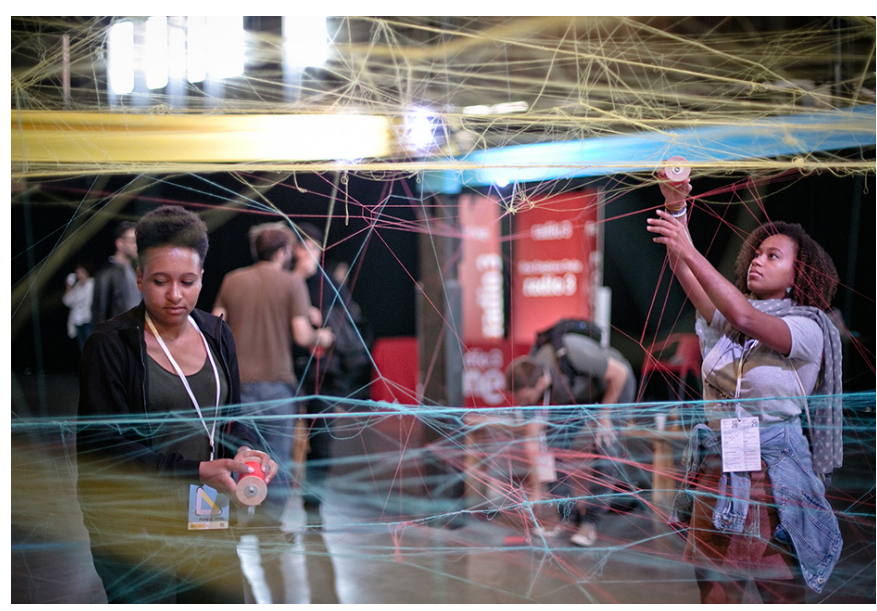

III Encuentro Cultura y Ciudadanía. Instalación de Carpintería Expandida. Matadero Madrid, 2017

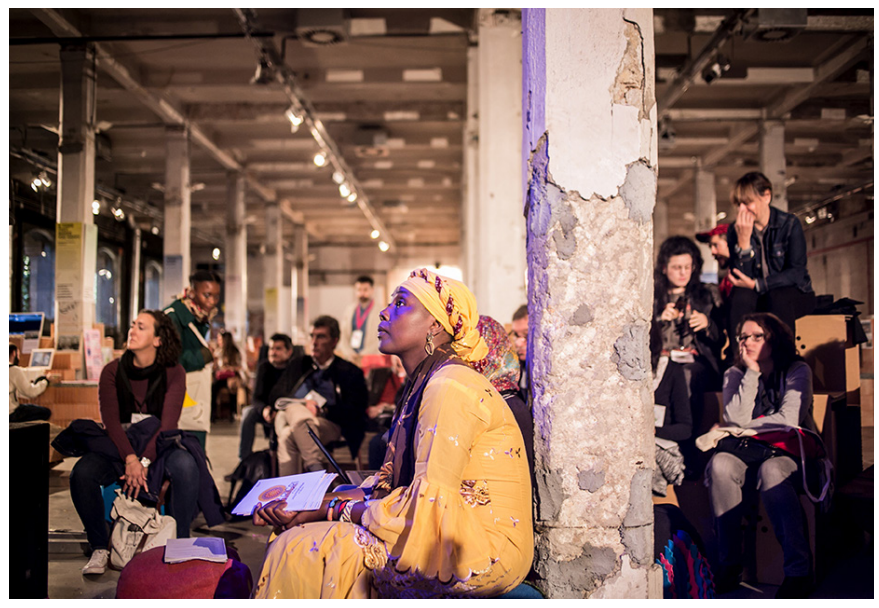

V Encuentro Cultura y Ciudadanía. Espacio público. Matadero Madrid, 2019

segunda edición la diseñamos alrededor de la noción poliédrica, dinámica e inacabada de "territorio" con la intención de examinar la cultura como sistema relacional complejo -ecosistema-, donde se establecen infinidad de flujos e interacciones e interactúan múltiples agentes a escala territorial. Las relaciones y tensiones entre lo urbano-rural, lo global-local o los centros-periferias vertebraron la segunda edición del encuentro en 2016, y en buena medida se han consolidado como nodos con gran peso específico dentro del programa.

Desde el comienzo se plantea como una de las líneasfuerza transversales el trabajo en torno a las prácticas culturales contemporáneas en el medio rural y la pro- 
pia noción de "ruralidad", conectando, de manera transversal, con la reflexión sobre el papel de la cultura en el cambio de narrativas e imaginarios y como dispositivo de desarrollo social en el actual escenario de crisis demográfica y ecológica. A partir de 2017 se inauguran líneas y espacios de trabajo específicos, como el foro Cultura y Ruralidades, de ámbito internacional y que va ya por su tercera edición, que en la línea del encuentro conjuga pensamiento y reflexión con la cartografía y puesta en valor de proyectos y experiencias; o el laboratorio de experimentación e innovación ciudadana Rural Experimenta, en colaboración con Medialab Prado, cuyo objetivo es favorecer el encuentro y la colaboración de personas de diversos contextos y saberes para el diseño en común de proyectos culturales para el ámbito rural.

En 2017 el III encuentro, bajo el título Acceso, acción, abordaba la reflexión sobre los derechos culturales en sus diferentes dimensiones y cómo estos habrían de verse reflejados tanto en la configuración de los sistemas y herramientas de acceso, participación y gobernanza de la cultura como en los modelos de política y apoyo institucional. En 2018 el IV encuentro profundizó en el análisis crítico de tres ejes centrales para la gestión cultural en la actualidad como son la educación, la mediación y el papel de los públicos. La última edición celebrada hasta la fecha, en 2019, estuvo dedicada a cuestionar y problematizar la categoría de "espacio público", en su doble dimensión material y simbólica, y a indagar caminos y posibilidades para su (re)apropiación, resignificación y coconstrucción a través de la cultura y sus procesos.

Los sucesivos encuentros han permitido desarrollar ideas y ampliar intereses y extender las vías de trabajo dentro del programa. A las específicas para el medio rural, se añaden otras como las cartografías y archivos digitales de proyectos, que operan como plataforma de difusión así como dispositivo de investigación y distribución de conocimiento y metodologías de trabajo; o la sección de "Pensamiento", un espacio editorial en línea para compartir modos de pensar y hacer, con un tiempo más pausado y reflexivo, a medio camino entre la publicación académica y el ensayo personal; u otras iniciativas concretas, como el Libro blanco de la creación, formación y desarrollo de públicos de la cultura, que parte de una propuesta de la Comisión de Cultura del Congreso.

En 2020 el encuentro afronta su sexta edición, la primera fuera de Madrid pues tendrá lugar en Tabakalera Donostia, marcada indeleblemente por la crisis sanitaria provocada por el COVID-19 y las secuelas que para la sociedad y la cultura tendrá la pandemia. Ello obliga a repensar algunos planteamientos y formatos, quizás también el propio espacio cultural e institucional que ocupan el encuentro y el orograma Cultura y Ciudadanía. Esta sexta edición, que se celebrará durante los días 11 y 12 de noviembre, se organizará temáticamente alrededor de las conexiones, intercambios y flujos entre "cultura, arte, ciencia, tecnología y naturaleza". Parte de una clara y explícita vocación transdisciplinar, o antidisciplinar, presente siempre en cualquier caso en nuestra actividad, desde la que abordar lo cultural como espacio antropológico holístico para el entendimiento de la realidad y la construcción conjunta de lo social, de lo común ¿Por qué unir cultura y ciencia? ¿Bajo qué premisas y condiciones? ¿Qué saberes y prácticas necesitamos? ¿Cómo repensamos lo humano? ¿Cómo abordar la soberanía digital? ¿Qué presentes vivimos y qué futuros compartidos anhelamos? ¿Cómo reflejarlo en las políticas y modelos culturales? ¿Quién y de qué modo narrarlo? Son estos algunos de los interrogantes, de absoluta pertinencia ahora, diríamos, sobre los que construiremos el encuentro Cultura y Ciudadanía 2020. 